\title{
Políticas públicas, formação de professores e a articulação escolar da leitura literária ${ }^{1}$
}

\section{Public policies, teacher training and school articulation of literary reading}

\author{
Angela Maria Hidalgo ${ }^{2}$ \\ Cláudio José de Almeida Mello ${ }^{3}$
}

\begin{abstract}
RESUMO
Com o objetivo de explicitar relações transversais entre políticas públicas, formação de professores, articulação escolar e promoção da leitura literária, este artigo analisa modelos de ensino de literatura no Brasil a partir do exame de documentos e de resultados da pesquisa empírica Concepções e práticas no ensino de literatura, realizada em uma escola pública de Ensino Fundamental e Médio do interior do estado do Paraná (Brasil). Conclusões apontam a necessidade de uma revisão de paradigmas que reconheça o texto literário em sua profunda relação com a vida, desde um ponto de vista estético, de forma a superar um modelo hegemônico de ensino de matriz formalista e estruturalista e focado na transmissão da teoria e da história literária. Nesse sentido, os referenciais da Estética da Recepção, do interacionismo bakhtiniano e do letramento consistem em uma importante contribuição, na medida em que permitem uma equalização de princípios teóricos acerca da literatura, da leitura, do texto e do leitor condizentes com encaminhamentos metodológicos de viés sociodiscursivo, voltados para a promoção da leitura literária como efetiva prática social.
\end{abstract}

Palavras-chave: políticas públicas; educação literária; formação do leitor; ensino de literatura.

DOI: $10.1590 / 0104-4060.36319$

1 Pesquisa financiada pela Fundação Araucária de Apoio ao Desenvolvimento Científico e Tecnológico do Estado do Paraná.

2 Universidade Estadual do Centro-Oeste (UNICENTRO), Departamento de Pedagogia. Guarapuava, Paraná, Brasil. Rua Salvatore Renna, 875. CEP 85015-430.

3 Bolsista da CAPES - Processo 1036/61-2. 


\begin{abstract}
With the aim of clarifying cross-relationships between public policies, teacher training, school articulation and promotion of literary reading, this article examines models of teaching literature in Brazil, from the examination of documents and results of the empirical research Conceptions and practice in the teaching of literature, carried out in a public elementary and high school in the state of Parana, Brazil. Conclusions indicate the need for a revision of paradigms that recognizes the literary text in its profound relationship with life from an aesthetic point of view, in order to overcome the current hegemonic model of teaching, characterized by the influence of formalism, structuralism and focused on the transmission of literary theory and history. Accordingly, the reference of the Aesthetics of Reception, of the interactionism of Bakhtin and literacy constitutes an important contribution, because it allows an equalization of theoretical principles about literature, reading, text and reader consonant with methodological proceedings based on a socio-discursive perspective, aimed at promoting literary reading as effective social practice.
\end{abstract}

Keywords: public policies; literary education; reader training; literature teaching.

\title{
Introdução
}

A formação de leitores no Brasil tem merecido a atenção de áreas e segmentos os mais diversos, incluindo universidades, escolas, bibliotecas, associações culturais, entidades da sociedade civil, dentre outros. Nos governos federal e estaduais, importantes iniciativas são desenvolvidas como programas de distribuição de livros e fomento à leitura. Essas ações, muitas delas com bom resultado no que diz respeito à aproximação da obra literária com o leitor, são desenvolvidas, entretanto, sem que haja uma articulação entre si, o que faz com que excelentes programas e projetos tenham um alcance restrito e de caráter efêmero.

Evidenciamos neste texto que as políticas públicas de âmbito federal no Brasil apenas recentemente explicitam o propósito de integrar os programas que buscam a ampliação do acesso às obras literárias a propósitos de formação de leitores. Diante do baixo índice de leitores no país, objetivamos explicitar as relações entre esta situação e um referencial teórico hegemônico na formação de professores nas universidades, de matriz formalista e estruturalista, focado na transmissão da teoria e da história literária, o que denota uma dissociação 
entre literatura e vida, um modelo reproduzido na Educação Básica que prejudica o interesse dos alunos pela leitura. Partindo desse quadro, indicamos na abordagem teórico-metodológica baseada na Estética da Recepção, no interacionismo bakhtiniano e no letramento uma contribuição significativa para a promoção da leitura literária, conforme verificamos em pesquisa empírica em uma escola do Ensino Fundamental e Médio no interior do estado do Paraná, que articulou, por meio da metodologia da pesquisa-ação, a revisão de processos de ensino-aprendizagem, a configuração da biblioteca escolar como um espaço de promoção da cultura e a participação dos pais.

\section{Políticas públicas para a leitura}

Apesar dos esforços governamentais realizados nas últimas décadas para a constituição de políticas públicas para a formação de leitores no país, os índices de leitura demonstram que as ações governamentais não têm surtido efeitos significativos. Devemos reconhecer que, em uma perspectiva histórica, para um país como o Brasil, são recentes os esforços nesta área, tendo em vista que a primeira instituição pública criada com objetivos de criação de bibliotecas públicas e fomento ao mercado editorial surgiu em 1937, com o Instituto Nacional do Livro. Apesar das realizações dessa entidade, "Ficou patente que a simples oferta de livros não garantiu formação de práticas de leitura. Esta é uma crítica que se faz às ações do instituto, que deixou de lado mecanismos de desenvolvimento e formação leitora [...]" (ROSA; ODDONE, 2006, p. 186).

$\mathrm{Na}$ área do incentivo à cultura em geral adquire destaque a lei Rouanet, que a partir de 1986 institui o Programa Nacional de Apoio à Cultura, a Comissão Nacional de Incentivo à Cultura e o Fundo Nacional de Cultura, os quais representam avanços na área da preservação e difusão de bens culturais e na área editorial.

Apenas a partir da década de 1990 os programas governamentais explicitam a preocupação de vincular os incentivos à edição de livros literários a projetos de formação de leitores. Nesta perspectiva, em 1992 é criado o Programa Nacional de Incentivo à Leitura (Proler), vinculado à Fundação Biblioteca Nacional, com a preocupação de promover uma política nacional de leitura, buscando, por meio da colaboração com comitês, estabelecer "uma relação horizontal de parceria e aprendizagem mútua” (BRASIL, 1992).

Em 1997 inicia-se a implementação do Programa Nacional Biblioteca da Escola (PNBE), com o objetivo de proporcionar o acesso à cultura e à informa- 
ção e contribuir para a formação do hábito de leitura dos alunos, professores e população em geral, distribuindo às bibliotecas escolares livros de literatura, de referência e para pesquisa (BRASIL, 2009). Há um esforço do governo federal em equipar as bibliotecas das escolas com livros de qualidade, selecionados por equipes de especialistas. Apesar da validade dessas ações, é necessário reconhecer que o desenvolvimento do hábito de leitura requer ações mais amplas, pois as escolas encontram-se despreparadas para a utilização do material recebido; não há, por exemplo, bibliotecários nas escolas, e os professores, com uma jornada de trabalho de 36 a 40 horas semanais, têm uma dificuldade muito grande de atuar como mediadores de leitura.

Como parte das ações do PNBE, em 2001 foi desenvolvido o Programa "Literatura em minha casa", que visava à distribuição de obras literárias aos alunos de $4^{\mathrm{a}}$ e $8^{\mathrm{a}}$ séries do Ensino Fundamental e suas famílias. Pesquisas acadêmicas (GUIMARÃES, 2010; ROSA; ODDONE, 2006) acerca desse programa evidenciam um impacto limitado de suas ações nas escolas, um baixo nível de informação dos gestores acerca do programa e problemas na distribuição do material tanto por parte dos níveis intermediários do programa quanto da escola. No colégio em que se realizou a pesquisa que subsidia este texto, os livros ficaram no acervo da biblioteca, sem que as famílias tivessem sequer conhecimento do programa.

Em 2006 foi lançado o Plano Nacional do Livro e Leitura (PNLL), com o objetivo de expandir a capacidade de leitura da população, incorporando-a ao cotidiano das pessoas. Para isso, uma série de programas e projetos foi desenvolvida em áreas de leitura, literatura e bibliotecas pelos governos federal, estaduais e municipais, além de outros segmentos da sociedade, em quatro eixos de ações: 1- Democratização do acesso; 2- Fomento à leitura e à formação de mediadores; 3- Valorização da leitura e comunicação; e 4- Desenvolvimento da economia do livro. Merece destaque a centralidade da busca pela elaboração de uma política pública voltada à leitura e ao livro, ou seja, a constituição de uma política de Estado $^{4}$. Toma-se como referência o conceito amplo de Estado na busca de um

4 Apoiados no conceito de Estado de Gramsci (1991), desvinculado, entretanto, das relações com a infraestrutura socioeconômica, intrínseca ao pensamento do filósofo italiano, os governos atuais, num contexto de crise econômica mundial, são pressionados pela necessidade de redução das despesas governamentais e acabam por efetivar o esvaziamento do papel do Estado na implementação e financiamento das políticas sociais. Com esta operação, de envolvimento da sociedade na execução das políticas públicas, contribuem para a desresponsabilização do Estado pelo seu financiamento (MONTAÑO, 2002). Indicamos a gravidade desta operação no Brasil, como se nota na incipiência das políticas de formação de leitores no país, que indica a necessidade de o governo federal, não obstante a positividade de envolvimento das demais instituições sociais nos projetos, manter-se como protagonista de todo o processo. 
maior envolvimento de vastos setores da sociedade no processo de implementação da proposta, como se pode observar no seguinte trecho do documento:

\begin{abstract}
Pretende-se conferir a este Plano a dimensão de uma Política de Estado, de natureza abrangente, que possa nortear e garantir alguma organicidade a políticas, programas, projetos e ações continuadas desenvolvidos no âmbito de ministérios [...], governos estaduais, municipais, empresas públicas e privadas, organizações da sociedade e de voluntários em geral, buscando evitar o caráter por demais assistemático, fragmentário e pulverizado com que se têm implementado essas iniciativas em nosso país, desde, pelo menos, o início do século XIX. (BRASIL, 2007, p. 19).
\end{abstract}

A constituição de políticas públicas não restritas ao âmbito de determinados governos, portanto não passíveis de substituição a cada mandato e aos interesses restritos dos partidos políticos, até por envolver também instituições da sociedade civil, tem sido apontada como forma de superação do caráter fragmentário das políticas públicas e como possibilidade de avanços na implementação de programas e projetos articulados, orgânicos e contínuos.

Apesar dos esforços do governo federal de desenvolver as políticas públicas, a situação da leitura no Brasil continua preocupante. De acordo com a pesquisa Retratos da leitura no Brasil, a média de leitura caiu de 4,7 livros por habitante/ano em 2007 para 4,0 em 2011 (FAILLA, 2012), incluindo os livros didáticos; ainda que essa redução possa significar apenas uma oscilação, ou que possa ser atribuída a alterações na coleta de dados, o atual índice continua baixo, se comparado a países desenvolvidos como a Espanha, com 10,3 livros por habitante/ano no mesmo ano da pesquisa no Brasil, ou a vizinhos como o Chile e a Argentina, com 5,4 e 4,6 livros por habitante/ano, respectivamente (HOYOS; SALINAS, 2012, p. 91-213). Os dados evidenciam que "políticas públicas, como a distribuição gratuita de livros a escolas e o abastecimento de bibliotecas têm se mostrado insuficientes para incidir significativamente sobre os números dessas estatísticas" (FAILLA, 2012, p. 7).

\title{
Motivação para a leitura
}

Esses dados indicam que falta muito para que os programas em desenvolvimento no país na área da leitura atinjam o público final a que se destinam, a 
população, escolar ou não. Como política pública, além de integrar as diversas áreas envolvidas na promoção da leitura, garantindo que elas interajam e se articulem de forma frequente, concatenada e colaborativa, um dos maiores desafios é que a leitura literária se caracterize como autêntica prática social, pois isso demanda uma revisão de paradigma em relação à própria concepção de arte e sua relação com a vida, sua inserção a pressupostos teóricos sobre a leitura e sua viabilização em metodologias de ensino. Dessa forma, os leitores estariam expostos a uma verdadeira experiência estética, relacionada ao prazer de ler, em oposição à leitura obrigatória imposta pela escola, o que certamente contribui para a penetração da leitura em um país. De acordo com estudo do Centro Regional de Fomento ao Livro na América Latina e no Caribe (CERLALC/UNESCO),

O prazer pela leitura é a diferença característica entre um leitor habitual e um leitor esporádico: a Espanha registra que 86\% leem por esse motivo; a Argentina $70 \%$ e o Brasil 49\%. O Brasil, Portugal, México e o Chile são aqueles países onde a leitura, por razões de atualização cultural e conhecimento geral, é maior (HOYOS; SALINAS, 2012, p. 194).

A situação é inversa, entretanto, quando a motivação para a leitura é a exigência escolar ou acadêmica: o Brasil aparece em primeiro lugar, com $36 \%$, e a Espanha com 7\%, justamente o país da comparação onde o número de leitores é maior. Esses dados permitem inferir que o componente da prática social nos hábitos leitores, relacionado à fruição estética no caso da literatura, possui relevância no advento da leitura em um país, conforme também observou Regina Zilberman (2012).

Assim, ao trabalhar a literatura desvinculada do interesse efetivo dos educandos, privilegiando os conteúdos teóricos e analíticos, como uma mera disciplina, a escola colabora para a diminuição paulatina do interesse espontâneo, autônomo e autêntico pela leitura. Como mostra a pesquisa Retratos da leitura no Brasil (FAILLA, 2012), a obrigação de ler encontra-se no polo oposto ao prazer pela leitura, o que sugere que a imposição, associada a metodologias de ensino em vigor, contribui mais para afastar os leitores do que para seduzi-los. E como lembra Pennac (1994), assim como não se pode obrigar ninguém a amar, não se pode impingir o prazer de ler, a realizar pela leitura uma efetiva prática social. Nesse sentido, 
Para que as atividades com os livros não fiquem à mercê do azar ou ocupem um lugar marginal - ou concedido quando se tenha terminado o "verdadeiro trabalho" educativo -, é necessário programar seu espaço e o tempo de atividades que se realizarão habitualmente e integrar estas atividades em programas completos de leitura, tanto por níveis educativos como em conjunto do itinerário educativo (COLOMER, 2010, p. 85 , tradução nossa).

É claro que a leitura feita por necessidade da disciplina escolar pode conduzir ao interesse do leitor. Como lembra Chartier (2007, p. 48), "Cada aluno deve descobrir, em sua experiência escolar, a lacuna que persiste entre seu desejo de saber e sua vontade de aprender; e deve descobrir assim também que a obrigação escolar não é sempre incompatível com o prazer de aprender". Mas mesmo nesse caso, a literatura é trabalhada a partir do interesse para a vida do leitor, diferente do modelo de ensino baseado na transmissão da historiografia literária e na análise literária intrínseca. Essas práticas transcendem a questão metodológica e revelam concepções de literatura que podem ser melhor compreendidas analisando-se a paulatina separação entre arte e vida, entre beleza e funcionalidade, que caracterizam uma visão moderna da arte, em geral.

\section{Separação entre arte e vida}

Em um longo período compreendido desde a antiguidade até a época moderna a compreensão da arte estava associada à sua relação com o mundo. Partindo da Poética de Aristóteles, verificamos que o conceito de mímesis extrapola a simples representação e atinge o foro da identificação entre o criador e a natureza; para o filósofo grego, a própria existência da arte pressupunha uma relação indissociável com o mundo, a que ela representa como uma possibilidade alternativa: de acordo com o conceito de verossimilhança, objeto e representação são equivalentes, aludem a uma pertença mútua mediada pela verdade poética.

Em Ars poetica, Horacio também manifesta a relação inexpugnável entre a arte e o mundo, já que as funções de deleitar e instruir orientam um efeito da arte sobre o homem e uma atitude ética deste em face da sociedade; além disso, a imitatio latina implica sempre reproduzir algo exterior à obra. Na Europa cristã dos primeiros séculos e ao longo da Idade Média mantém-se a relação entre arte e mundo pela via da difusão e glorificação da palavra de Deus, em que a 
poesia estava a serviço da religião. E quando a poesia se libera da religião, no Renascimento, ela retorna aos critérios antigos. Então, pede-se que ela seja bela e verdadeira, conforme o pensamento de Boileaux (TODOROV, 2007).

É nos tempos modernos que se rompe essa concepção de arte, calcada em sua forte relação com o mundo, por meio da secularização da religião e da sacralização da arte. No primeiro caso, o poeta se compara a Deus, por criar um objeto finito, um microcosmos; ele cria, portanto, um objeto paralelo ao mundo físico, um universo independente e perfeito em sua coerência interna. No segundo caso, altera-se a destinação da poesia, que não é mais a de imitar o mundo, senão criar a beleza, em si mesma; neste sentido, não é o poeta que se assemelha ao criador, mas sim a obra, em sua perfeição, que é amada por si própria, como se ama a Deus (TODOROV, 2007).

Assim, nos séculos XVII e XVIII a contemplação adquire grande valor, dado o juízo do gosto e o sentido da beleza como entidades autônomas. Claro que antes a beleza era considerada e apreciada, mas ela tinha uma relação exterior com o mundo: a música e as representações nas igrejas destinavam-se a glorificar a Deus; o camponês admira sua ferramenta, mas ela tem uma utilidade; as pinturas nos palácios eram belas, mas também tinham a função de impressionar os visitantes. A partir da época em torno do Iluminismo europeu, entretanto, a beleza se dissocia de sua funcionalidade em face do mundo, daí o interesse em analisá-la autonomamente, em avaliar o seu valor estético. Essa mudança se fez sentir no ensino de literatura: "O ensino das letras na França ilustra esse passo com cem anos de atraso: enquanto que, até meados do século XIX, esse ensino advinha da retórica (aprendia-se a escrever), a partir daquele momento adota a perspectiva da história literária (aprende-se a ler)" (TODOROV, 2007, p. 47, tradução nossa).

No início do século XX, os movimentos das vanguardas radicalizam a separação entre arte e mundo; artistas abstracionistas como Kandinsky buscam eliminar a figurativização e criar formas abstratas que abolem a representação da realidade concreta (GOMBRICH, 1997, p. 570-573).

\section{Estudos literários e ensino de literatura}

Como aconteceu em outras áreas, os estudos literários assumem essa separação em seus objetos de estudo. Podemos apontar como expoente dessa tendência o Formalismo Russo, que, ao concentrar-se na natureza intrínseca da obra poética, reivindica uma negação da sua relação com o contexto externo. 
Autores como Eikenbaum recusam elementos extratextuais como fonte de explicação da obra literária, e adotam o método descritivo e morfológico para buscar no próprio texto as características que lhe dotam de literariedade; para o autor, obra é forma, um sistema em que todos os elementos se integram (ERLICH, 1974, p. 245-252).

Nessa tendência de concentração no texto em detrimento da realidade exterior encontra-se também o Estruturalismo, que já em sua origem buscava compreender de modo sincrônico as relações formais dos elementos da língua, em sua constituição interna, abolindo o exame da linguagem falada e da relação externa da língua com os objetos concretos no mundo empírico (SAUSSURE, 1989). No campo dos estudos literários, a partir das décadas de 1960 e 1970, o Estruturalismo tem uma grande entrada nas universidades europeias, sobretudo a partir dos acontecimentos de maio de 68 na França, cujo clima de liberação permitiu o abandono da explicação do texto a partir da biografia do autor, da história, do contexto e de um marco teórico e nacional, dando lugar a uma orientação estruturalista, com a radicalização do estudo interno do texto e a análise dirigida pelas categorias da teoria literária (TODOROV, 2007, p. 30). Nessa época, o estudo do sentido do texto e sua relação com a realidade eram vistos com receio; essa interpretação, não alcançada pelas vias científicas, ficava com profissionais como jornalistas, escritores e críticos de jornais.

Contribuiu ainda para a ênfase da teoria e da explicação do entorno do texto em lugar do sentido da obra a predominância nos estudos universitários por mais de um século da historiografia literária, com a apresentação das causas (aspectos sociais, políticos, psicológicos, étnicos) e consequências da obra literária (seu impacto no público, sua disseminação e sua influência sobre outros autores), um efeito da força do pensamento positivista nas ciências humanas, que engendrou nos estudos literários uma historiografia linear e esquemática, incapaz de explorar as profundas relações entre arte e vida. Afinal, "A tradição universitária [...] não se concebia a literatura como a encarnação de um pensamento e uma sensibilidade, nem como uma interpretação do mundo" (TODOROV, 2007, p. 33, tradução nossa).

\section{Formação de professores e ensino de literatura}

Quando os estudos formalistas e estruturalistas chegam de uma forma mais ampla ao ensino universitário no contexto brasileiro, a tradição historiográfica na literatura já havia constituído um modelo cristalizado de ensino, estendido ao 
ensino secundário: definições de literatura, análise literária, história da literatura, biografia de autores e características de estilos de época, apresentados diacronicamente, em uma evolução linear de orientação positivista, fato observável na constituição atual do ensino de literatura no Ensino Médio, em geral uma aplicação simplificada do modelo difundido nos cursos de Letras.

É o que mostra o estudo realizado por Vanderleia da Silva Oliveira (2007) em sete cursos de Letras de instituições públicas no estado do Paraná, nos quais a pesquisadora revela um modelo arraigado de transmissão das histórias da literatura, retomando uma tradição de histórias literárias que remontam à segunda metade do século XIX e atravessam o século XX: o Curso de Literatura Nacional de Cônego Fernandes Pinheiro, de 1862; a Pequena história da Literatura Brasileira, de 1919, de Ronald de Carvalho; no mesmo ano, Lições de Literatura Brasileira, de José Ventura Boscoli; História da Literatura Nacional, de 1930, de Jorge Abreu; Noções de história da literatura brasileira, de 1931, de Afrânio Peixoto; História da Literatura brasileira, de 1939, de Bezerra de Freitas. Nessa tradição, foi grande a influência dos três grandes críticos literários já em sua época: a História da literatura brasileira de Sílvio Romero, em 1888, de orientação determinista baseada sobretudo na raça; a História da literatura brasileira de José Veríssimo, em 1912, com a perspectiva de valorização do nacional; e estudos como "Ponto de vista para o estudo da literatura brasileira", de Araripe Junior, publicado em 1866, nos quais se verifica uma perspectiva determinista, focada no meio. A análise dessa influência permite a Cairo (1997, p. 41) concluir que "O esquema da história da literatura brasileira inventado pelos críticos naturalistas repete-se ao longo da história da literatura brasileira até a exaustão e cai na rotina na medida em que prejudica a visão crítica das obras".

No início da segunda metade do século XX, surgem duas grandes obras que superam o modelo positivista, o qual entretanto já se encontrava disseminado nos cursos de Letras e, por consequência, também no ensino secundário, A literatura no Brasil, de 1955, dirigida por Afrânio Coutinho, orientada pelo critério da periodização estilística; e A formação da literatura brasileira, de 1959, de Antonio Candido, um estudo sobre os momentos decisivos que deram lugar ao surgimento de uma literatura nacional, compreendida como um sistema literário, que inclui autores secundários, superando o historicismo e a concentração no cânone, repetidos desde Sílvio Romero.

Além dessas, outra obra importante surgida nessa época é a História concisa da literatura brasileira, 1970, de Alfredo Bosi, obra que, "sem dúvida, é aquela que melhor define a relação atual entre história literária e ensino de literatura, posto que é presença unânime nos cursos de Letras" (OLIVEIRA, 2007, p. 68-69). 
Em âmbito nacional, outro estudo acadêmico de Marly Amarilha de Oliveira (1982) já havia constatado um modelo hegemônico de ensino de literatura nos cursos de Letras de 25 universidades brasileiras, nos quais a transmissão da historiografia literária e a ênfase na periodização mostraram-se proeminentes, em detrimento da interpretação da obra como objeto estético.

Há, claro, no meio universitário uma heterogeneidade nos ramos de estudos, muitas vezes contraditórios. Mas a preponderância é da tendência que se recusa a enxergar a literatura como um discurso sobre o mundo (TODOROV, 2007, p. 33). Assim, é aquela tendência hegemônica da formação em nível superior que, via de regra, orientará a prática de ensino dos professores nas escolas da Educação Básica, como mostra o trabalho acadêmico de Marisa Cardoso Piedras (2007) sobre o ensino de literatura em quatro escolas privadas de Ensino Médio do município de Porto Alegre-RS, nas quais "o padrão de ensino da história da literatura permanece submisso aos estilos epocais, à periodologia e à concepção evolutiva da historiografia". Segundo a pesquisadora,

Os planos de conteúdos, tanto nas escolas particulares como nas públicas, mostram uma história da literatura com uma percepção historicista de evolução linear, baseada na continuidade. Não há fragmentação no alinhamento dos assuntos literários, que se organizam temporalmente, do mais distante ao mais próximo (PIEDRAS, 2007, p. 84).

Acompanhando a transmissão da historiografia literária, outra presença constante nas aulas de literatura na Educação Básica são os exercícios de análise literária, seja nos textos em prosa, geralmente com o objetivo de identificar na estrutura narrativa os tipos de personagens, espaço e tempo, assinalando uma filiação ao estudo do formalista Vladimir Propp (1983), seja nas obras em verso, estudando os tipos e nomes das figuras de linguagem, a escansão de versos, os tipos de rima, enfim, uma análise intrínseca das particularidades da linguagem poética, um modelo reconhecidamente formalista. Assim,

o contato maior que qualquer aluno do ensino médio tem com o texto literário de fato se dá seja nas abonações e exemplos que auxiliam na compreensão das regras e formações da língua portuguesa, seja nas próprias aulas de literatura, que se resumem principalmente ao ensino da história e dos gêneros literários (MEIRA, 2009, p. 9). 
Como o foco do ensino se dá em estudos teóricos e históricos sobre o texto, a obra literária em si boa parte das vezes é utilizada para exemplificar as análises indicadas, em geral com fragmentos e resumos, um modelo difundido no ensino secundário subsidiário daquele praticado no ensino superior; neste, é natural que os estudantes, futuros profissionais das letras, tenham que conhecer as correntes críticas e os meandros da análise literária; o que não significa que naquele isso seja pertinente, pois " $O$ ensino secundário, que não se dirige aos especialistas da literatura mas sim a todos, não pode ter o mesmo objeto: é a literatura em si que está destinada a todos, não os estudos literários" (TODOROV, 2007, p. 35, tradução nossa).

\section{Leitura literária como prática social}

A partir da década de 1980 chegam ao Brasil estudos que propiciam uma revisão de conceitos fundamentais para a proposição de encaminhamentos metodológicos no sentido da promoção da leitura. Um dos principais é o arcabouço teórico formulado por Mikhail Bakhtin, que concebe a língua como um fenômeno social. Centrado no estudo da parole (fala), por concebê-la como responsável pela manutenção da dinâmica viva da língua, o autor chega à compreensão de que toda palavra é dialógica, uma vez que participam de sua construção um "eu" (enunciador) e um "outro" (enunciatário), de modo que há em todo texto, escrito ou oral, uma interação verbal e social, inserida em um contexto, no qual se articulam os discursos (BAKHTIN, 1999; 2003).

Dessa formulação sociodiscursiva da linguagem deriva um conceito de leitura como interação entre texto e leitor, e um pensamento pedagógico que valoriza a prática social nos processos de ensino-aprendizagem. De acordo com essa proposição, surge também na década de 1980 o conceito de letramento no ensino de língua (KLEIMAN; SIGNORINI, 1995; SOARES, 1998), fundamental para a valorização do trabalho com conteúdos significativos para os educandos. No caso da literatura, entendemos que a leitura efetiva é aquela em que o sujeito leitor se identifica com a leitura, cujo interesse ou fruição propicia uma autêntica prática social, aproximando, assim, literatura e vida.

É na década de 1980 também que se disseminam no Brasil os estudos da teoria da Estética da Recepção, que propõem uma nova lógica para a valorização do texto literário, ao considerar o objeto estético em função do valor que lhe atribui o leitor, razão pela qual propõem que a recepção seja considerada na historicidade das obras. Jauss (1994) condena as histórias literárias de fun- 
damentação positivista, que dispõem de forma enrijecida uma sucessão cronológica, uma repartição de gêneros e um rol linear de grandes autores e suas obras, um modelo que não reconhece a historicidade da recepção e se fixa em um cânone inquestionável (ZILBERMAN, 1989, p. 30-32). Fundamentado na hermenêutica, que explicou a compreensão humana como um processo em que o sujeito intérprete realiza uma fusão de horizontes, um diálogo entre o objeto e o horizonte de expectativas (conhecimentos prévios) do leitor, Jauss (1994) explica que a obra literária é um complexo linguístico-imaginário que possui pontos de indeterminação, os quais são preenchidos no ato da leitura. É o leitor, portanto, quem preenche esses pontos e realiza um todo compreensível, é ele quem recria o objeto estético em um diálogo produtivo com a obra.

\section{Pesquisa, concepções e práticas no ensino de literatura}

A partir dessa fundamentação teórico-metodológica, o grupo de pesquisa Literatura e Educação ${ }^{5}$ realizou de 2007 a 2012 a pesquisa Concepções e práticas no ensino de literatura, com o objetivo de verificar, em um primeiro momento, em que medida estavam presentes em uma situação específica políticas públicas para a leitura, concepções e práticas no ensino de literatura, e posteriormente como a mesma comunidade escolar respondia ao desenvolvimento de projetos de ensino de literatura pautados pelos referenciais do dialogismo, da Estética da Recepção e do letramento, nos quais se propõe uma aproximação entre arte e vida, isto é, em que a literatura é trabalhada de maneira significativa para os sujeitos leitores.

Tendo como campo de estudo uma escola pública de Ensino Fundamental e Médio do município de Guarapuava-PR, constatou-se inicialmente uma ausência de ações articuladas pelos programas de leitura governamentais, e mesmo um desconhecimento de sua existência. O documento mais citado pelas professoras e equipe pedagógica foram as Diretrizes Curriculares de Língua Portuguesa e Literatura para a Educação Básica do Paraná, até por ser objeto de estudo em cursos de formação continuada promovidos pela Secretaria de Estado da Educação; o documento embasa processos de ensino-aprendizagem, entretanto não orienta a forma como se deve dar, como parte do processo pedagógico, a

5 Grupo de pesquisa criado em 2007 por pesquisadores das áreas de Letras e Educação da Universidade Estadual do Centro-Oeste e da Universidade de Coimbra (http://sites.unicentro.br/ wp/literaturaeeducacao/). 
atuação do entorno social mais amplo que envolve o ato da leitura, como, por exemplo, a participação dos pais.

Os procedimentos da pesquisa na escola iniciaram-se então com a realização de diagnósticos sobre as experiências leitoras de uma turma de cada ano, do $6^{\circ}$ ao $9^{\circ}$ ano do Ensino Fundamental e do $1^{\circ}$ ao $3^{\circ}$ ano do Ensino Médio, em três áreas: 1) processos de ensino-aprendizagem; 2) biblioteca escolar; e 3) participação dos pais.

No primeiro caso, os diagnósticos apontaram uma concepção de leitura como decodificação, e um uso do texto literário basicamente para o ensino da taxionomia da estrutura narrativa ou de figuras poéticas, além do ensino de língua, sobretudo em relação à gramática normativa e à interpretação de texto, de acordo com o indicado nos livros didáticos. Nas observações das aulas, constatou-se que apenas uma das cinco professoras (de $6^{\circ}$ ano) já abordava a literatura pelo seu valor estético, com atividades lúdicas e criativas desenvolvidas de forma não utilitarista, pelo valor estético do texto literário e pelo prazer da leitura.

Quanto à biblioteca escolar, os diagnósticos realizados por meio de observação direta, de questionários com alunos e de entrevistas com o profissional responsável pela biblioteca, com a direção da escola e com a equipe pedagógica, indicaram que esse espaço funcionava como um depósito de livros e materiais diversos, muitos deles não didáticos, incluindo materiais obsoletos; os alunos não tinham acesso direto aos livros, que não estavam catalogados; a servidora que atuava nesse espaço não tinha nenhuma formação pedagógica ou técnica para atuar em bibliotecas; e os alunos somente podiam permanecer no recinto por solicitação das professoras, para realização de estudos ou por sanção devido a atraso ou indisciplina.

Na terceira área, os pais não tinham nenhuma participação na formação leitora: não realizavam atividades compartilhadas de leitura em casa; nunca tinham visitado a biblioteca escolar; não tinham o hábito de leitura.

Esses diagnósticos foram compartilhados com os professores de todas as disciplinas em uma reunião pedagógica na escola, e a partir de então a comunidade escolar dispôs-se a envolver-se no que ficou conhecido como o "projeto de leitura". Tendo em vista a adoção da metodologia da pesquisa-ação, as análises dos diagnósticos deram lugar ao estudo de textos teórico-metodológicos, os quais orientaram intervenções com projetos de leitura em cada uma dessas três áreas, de forma articulada.

No primeiro caso, embasados pela teoria da Estética da Recepção, pela concepção interacionista de linguagem e pelo letramento, o grupo das professoras de língua portuguesa passou a desenvolver uma série de atividades de leitura com foco no leitor, tais como: concessão de tempo de leitura literária livre em sala de aula, sugestão de leituras para casa, hora da leitura (em que toda a 
escola para durante uma hora-aula para leitura livre), caderno de leitura (com depoimentos sobre a experiência leitora), escrita criativa, leituras compartilhadas entre os alunos e com a professora, com atividades de análise não como um fim em si, mas como meio de aprofundar a cognição e possibilitar uma maior fruição do texto literário.

No segundo caso, a leitura de textos como "O caminho dos livros: da biblioteca à comunidade", de Vera Teixeira de Aguiar (2006), orientaram uma completa revitalização da biblioteca, que ficou fechada durante as férias para o descarte de materiais inúteis, reorganização do espaço de acordo com orientações da biblioteconomia, catalogação dos livros, instituição do cantinho da leitura, criação de espaço mais acessível para os gibis, aquisição de livros infantis e juvenis, empréstimos de livros aos pais de alunos etc. Na busca da constituição da biblioteca como um espaço de promoção da cultura foram desenvolvidas atividades como encontros com escritores, palestras culturais, saraus, hora do conto, contação de histórias, dentre outros.

$\mathrm{Na}$ terceira área, foram realizados quatro encontros com os pais ao longo do ano de 2010. No primeiro, 106 de um total de 198 pais e mães de alunos de $6^{\circ}$ ano estiveram presentes, e foram unânimes em manifestar o interesse de participar do projeto de leitura, assim como em reconhecer a importância da leitura literária para seus filhos, inclusive os pais analfabetos. Nos encontros seguintes, eles foram orientados a como acompanhar as atividades de leitura em casa, em atividades tais como: interessar-se pelos livros que os filhos levavam da escola; valorizar os depoimentos sobre a leitura; reservar um horário e um espaço em casa para a leitura; ler junto com os filhos; emprestar livros e participar de outras atividades da biblioteca escolar; registrar a experiência com a literatura no caderno de leituras.

Dentre os resultados qualitativos obtidos em entrevistas com os sujeitos da pesquisa, destacam-se: com os alunos, uma melhoria sensível no interesse pelos livros e pela leitura literária, um maior apreço pelo espaço da biblioteca, uma abertura para partilhar as leituras com colegas e as famílias, e disposição para usar o tempo de ócio em casa para a leitura literária; com os pais, uma valorização da leitura literária e participação nas atividades de leitura demandadas pela escola; com os professores, uma maior clareza do porquê se ensinar literatura, percepção compartilhada pelos discentes universitários de iniciação científica e de estágio; com a direção e com as pedagogas, uma convicção da importância de fomentar a promoção da leitura literária, demonstrada pela inserção do plano de leitura na proposta pedagógica da escola e pela destinação de mais uma funcionária e uma professora para atuarem na biblioteca; com as servidoras da biblioteca, uma consciência da dimensão pedagógica de seu trabalho, ainda que não tenha havido ações específicas nesse sentido. Os depoimentos das professoras de língua 
portuguesa, entretanto, são incisivos no que diz respeito à dificuldade de tempo para dedicar-se à leitura de obras literárias, ao estudo e à preparação e execução das atividades, viabilizadas durante o projeto de pesquisa pela participação dos alunos de iniciação científica e de estágio do curso de Letras.

\section{Conclusões}

Tendo em vista o baixo índice de leitura no Brasil, não obstante a percepção de que este é um problema histórico relacionado ao desenvolvimento econômico, político e social do país, são prementes os esforços na direção da normalização da leitura na sociedade para que, juntamente com a melhora no nível socioeconômico da população, com a possibilidade de maior acesso aos bens materiais e culturais produzidos socialmente, ocorram mudanças nos aspectos culturais como o hábito de leitura. Dentre esses esforços, destacamos a revisão de paradigma teórico e metodológico na formação inicial nos cursos de Letras, assim como na formação continuada de professores em exercício, que considere o texto literário em sua profunda relação com a vida desde um ponto de vista estético, em prol da promoção da leitura literária. Como insiste Todorov (2007, p. 97, tradução nossa), precisamos retomar a relação autêntica da literatura com a vida, pois, "Se o objeto da literatura é a própria condição humana, aquele que a lê e a compreende se tornará não um especialista em análise literária, mas sim um conhecedor do ser humano". Nessa revisão, pesquisas como a citada Concepções e práticas no ensino de literatura revelam que os referenciais da Estética da Recepção, do interacionismo bakhtiniano e do letramento consistem em uma importante contribuição, na medida em que permitem uma equalização de princípios teóricos acerca da literatura, da leitura, do texto e do leitor condizentes com encaminhamentos metodológicos de viés sociodiscursivo (GUIMARÃES, 2007), voltados para a promoção da leitura literária como efetiva prática social.

Os esforços dos educadores na constituição de uma referência teórico-metodológica coerente com as necessidades socioculturais dos alunos e de suas famílias demandam a existência de políticas públicas para a promoção da leitura, com o necessário incremento do investimento público, que integrem as diversas áreas e agentes envolvidos, como as pesquisas, a formação de professores e mediadores de leitura, a composição e atualização dos acervos das bibliotecas, a extensão universitária, a integração entre Ensino Superior e a Educação Básica. 
No âmbito da escola, uma das conclusões mais importantes da pesquisa realizada diz respeito à percepção da relevância de a escola integrar as diversas atividades (leitura compartilhada, mediação de leitura), as disciplinas (Língua, Literatura, Artes) e os agentes (professores, bibliotecários, pais de alunos) nos processos de ensino-aprendizagem envolvidos na promoção da leitura literária, de forma sistematizada em um plano global de leituras que extrapole as séries anuais, na linha do que registra Colomer (2007). Assim, a articulação escolar do ensino da literatura em sua dimensão estética, cultural e social, sob uma perspectiva interdisciplinar, pode atuar no sentido de resgatar a noção de arte em sua relação com a vida, como princípio que orienta objetivos e metodologias de ensino.

\section{REFERÊNCIAS}

AGUIAR, Vera Teixeira de. O caminho dos livros: da biblioteca à comunidade. In: AGUIAR, Vera Teixeira de; MARTHA, Alice Áurea Penteado (Org.). Territórios da leitura: da literatura aos leitores. São Paulo: Cultura Acadêmica; Assis: NEP, 2006. p. 255-267.

BAKHTIN, Mikhail M. Estética da criação verbal. Trad. Paulo Bezerra. São Paulo: Martins Fontes, 2003.

BAKHTIN, Mikhail (Volochinov). Marxismo e filosofia da linguagem. Trad. de Michel Lahud e Yara Frateschi. 9. ed. São Paulo: Hucitec, 1999.

BRASIL. Ministério da Educação; Ministério da Cultura. Plano Nacional do Livro e Leitura. Brasília: MEC, MinC, 2007.

Programa Nacional Biblioteca da Escola. Brasília: MEC: 2009. Disponível em: $<$ http://www.fnde.gov.br/home/index.jsp?arquivo=biblioteca_escola.html\#historicO $>$. Acesso em: 20/08/2009.

BRASIL. Decreto ${ }^{\circ}$ 519, de 13 de maio de 1992. Institui o Programa Nacional de Incentivo à Leitura. Diário Oficial da União, Brasília, DF, 14 maio 1992. Disponível em: $<$ http://presrepublica.jusbrasil.com.br/legislacao/113527/decreto-519-92>. Acesso em: 21/08/2013.

CAIRO, Luiz Roberto Velloso. História da literatura, literatura comparada e crítica literária: frágeis fronteiras disciplinares. Poligrafias: Revista de Literatura Comparada, México-D.F., n. 2, p. 35-45, 1997.

CHARTIER, Anne-Marie. L'école et la lecture obligatoire. Paris: Retz, 2007. 
COLOMER, Teresa. Andar entre livros: a leitura literária na escola. São Paulo: Global, 2007. . Introducción a la literatura infantil y juvenil actual. 2. ed. Madrid: Sintesis, 2010. ERLICH, Victor. El formalismo ruso. Barcelona: Editorial Seix Barral, 1974.

FAILLA, Zoara (Org.). Retratos da leitura no Brasil 3. São Paulo: Imprensa Oficial do Estado de São Paulo: Instituto Pró-Livro, 2012.

GOMBRICH, E. H. La historia del arte. Trad. Rafael S. Torroella. 16. ed. Barcelona: Círculo de Lectores, 1997.

GRAMSCI, Antonio. Maquiavel, a política e o estado moderno. Trad. Luiz Mário Gazzeano. 8. ed. Rio de Janeiro: Civilização Brasileira, 1991.

GUIMARÃES, Ana Maria de Mattos et al. (Orgs.). O interacionismo sociodiscursivo: Questões epistemológicas e metodológicas. Campinas: Mercado Aberto, 2007.

GUIMARÃES, Janaína. Biblioteca escola e politicas públicas de incentivo à leitura. Dissertação (Mestrado) - Programa Pós-Graduação Educação, Universidade Estadual Júlio Mesquita Filho. Presidente Prudente, 2010.

HOYOS, Bernardo Jaramillo; SALINAS, Lenin Monak. Comportamento do leitor e hábitos de leitura: comparativo de resultados em alguns países da América Latina. In: FAILLA, Zoara (Org.). Retratos da leitura no Brasil 3. São Paulo: Imprensa Oficial do Estado de São Paulo: Instituto Pró-Livro, 2012. p. 191-213.

JAUSS, Hans Robert. A história da literatura como desafio à teoria literária. Trad. Sérgio Tellaroli. São Paulo: Ática, 1994.

KLEIMAN, Angela; SIGNORINI, Inês (Org.). Os significados do letramento. Campinas: Mercado das Letras, 1995.

MEIRA, Caio. Apresentação. In: TODOROV, T. A literatura em perigo. Rio de Janeiro: DIFEL, 2009.

MONTAÑO, Carlos. O terceiro setor e a questão social: crítica ao padrão emergente de intervenção social. São Paulo: Cortez, 2002.

OLIVEIRA, Marly Amarilha de. O ensino de Literatura brasileira na universidade: subsídios para uma abordagem crítica. Dissertação (Mestrado) - Faculdade de Educação, Universidade Federal de Santa Catarina. Florianópolis, 1982.

OLIVEIRA, Vanderleia da Silva. História literária nos cursos de Letras: cânones e tradições. Tese (Doutorado) - Programa de Pós-Graduação em Letras, Universidade Estadual de Londrina. Londrina, 2007.

PENNAC, Daniel. Como um romance. Rio de Janeiro: Rocco, 1994.

PIEDRAS, Marisa Cardoso. Escola e história da literatura em diálogo. Dissertação (Mestrado) - Programa de Pós-Graduação em Letras, Pontifícia Universidade Católica do Rio Grande do Sul. Porto Alegre, 2007. 
PROPP, Vladimir. Morfologia do conto. Lisboa: Vega, 1983.

ROSA, Flávia G. M. G; ODDONE, Nanci. Políticas públicas para o livro, leitura e biblioteca. Ci. Inf., Brasília, v. 35, n. 3, p. 183-193, set./dez. 2006. Disponível em: <http:// www.scielo.br/ pdf/ci/v35n3/v35n3a17.pdf>. Acesso em: 21/09/2013.

SAUSSURE, Ferdinand. Curso de linguística geral. 15. ed. São Paulo: Cultrix, 1989.

SOARES, Magda. Letramento: um tema em três gêneros. Belo Horizonte: Autêntica, 1998.

TODOROV, Tzvetan. La literatura en peligro. Trad. Isabel M. Baillo. Barcelona: Galáxia Gutenberg, 2007.

ZILBERMAN, Regina. Estética da recepção e história da literatura. São Paulo: Ática, 1989.

. Ler é dever, livro é prazer?. In: FAILLA, Zoara (Org.). Retratos da leitura no Brasil 3. São Paulo: Imprensa Oficial do Estado de São Paulo: Instituto Pró-Livro, 2012. p. 117-122.

Texto recebido em 20 de fevereiro de 2014.

Texto aprovado em 03 de março de 2014. 
